\title{
Interactive comment on "The Detailed Emissions Scaling, Isolation, and Diagnostic (DESID) module in the Community Multiscale Air Quality (CMAQ) Modeling System version 5.3" by Benjamin N. Murphy et al.
}

\section{Anonymous Referee \#1}

Received and published: 1 February 2021

This paper describes a new feature of tracking and modifying emission inputs in the CMAQ v5.3. It is delightful to read the well-organized manuscript, with clear explanation of the workflow and functionality of DESID and its implementation in the CMAQ model. The new development is a desired tool that will make it easier for researchers and regulatory model users who are not an emission expert to study sophisticated emission perturbation simulations to quantify source-receptor relationships. This manuscript provides a detailed description of the new feature that can benefit the CMAQ user community. Therefore, I recommend the publication of this manuscript, with some sug- 
gestions to further improve the usability of this tool.

1) While the description is comprehensive, it will be useful for the authors to provide some use cases with figures showing the emission changes or CMAQ output changes. 2) It should be pointed out the using some of the DESID features will require generating and retaining sector-level emission files and all more space to run the model, although most of these files are two dimensional. 3) Figure 1 shows the workflow of DESID in which both natural and anthropogenic source s 4) Future direction: All inline emission processes, including sea-salt, dust, biogenic and plume rise, are included in the VDIFF subroutine. As the addition of DESID, the emission module may be too complicated to be treated as a sub-subroutine. Has the team considered having emission as a separate subroutine in the science process file?

Interactive comment on Geosci. Model Dev. Discuss., https://doi.org/10.5194/gmd-2020-361, 2020. 